\title{
PENYULUHAN EDUKASI STUNTING BALITA PADA MASA PANDEMI COVID19 DI POSYANDU MELATI II KECAMATAN SUKA JAWA
}

DOI: https://doi.org/10.33024/jkpm.v4i4.3697

\author{
Dwi Robbiardy Eksa ${ }^{1}$, Itsna Annisa ${ }^{2}$, Ringgo Alfarisi ${ }^{3}$, Jordy \\ Oktobiannobel $^{4}$, Nopi Sani ${ }^{5}$, Sri Maria Puji Lestari ${ }^{6}$ \\ 1-6Fakultas Kedokteran Universitas Malahayati
}

Disubmit: 16 Januari 2021 Diterima: 01 Agustus 2021 Diterbitkan: 04 Agustus 2021

Email Korespondensi: Indriaprianti02041998@gmail.com

\begin{abstract}
ABSTRAK
Di negara berkembang stunting menjadi masalah kesehatan masyarakat yang serius. Stunting disebabkan kekurangan asupan gizi dalam waktu lama pada masa 1000 hari pertama kehidupan (HPK) yang merupakan masa kritis. Kurang nya pengetahuan orang tua akan sangat berpengaruh pada asupan gizi anak. Oleh karenanya diperlukan upaya pencegahan terjadinya stunting pada balita baik secara langsung (intervensi gizi spesifik) maupun secara tidak langsung yang melibatkan lintas sektor dan masyarakat dalam penyediaan pangan, air bersih dan sanitasi, penangulangan kemiskinan, pendidikan, sosial dan sebagainya. Tujuan dari kegiatan ini adalah untuk meningkatkan pengetahuan para orang tua betapa penting nya menjaga asupan gizi anak- anak bahkan pada saat kehamilan untuk mencegah stunting. Metode yang digunakan dalam kegiatan ini yaitu penyuluhan kepada orang tua balita yang melaksanakan posyandu di Posyandu Melati 2 Kecamatan Sukajawa mengenai pentingnya memonitoring tumbuh kembang anak dengan cara rutin memeriksakannya ke posyandu untuk melihat ada tidaknya resiko terjadinya stunting pada balita. Kegiatan ini dilaksanakan pada tanggal 22 Desember 2020 di Posyandu Melati 2 Kecamatan Sukajawa. Hasil dari kegiatan ini adalah meningkatnya pengetahuan dan wawasan orang tua tentang pentingnya pemberian nutrisi yang baik serta datang ke posyandu untuk mengukur tinggi badan dan berat badan balita agar dapat memonitoring pertumbuhan anak - anaknya serta mengetahui tanda dan gejala apa saja yang timbul pada stunting pada balita dan bagaimana cara mencegahnya.
\end{abstract}

Kata Kunci: Penyuluhan, Stunting, Balita

\begin{abstract}
In developing countries stunting is a serious public health problem. Stunting is caused by lack of nutritional intake for a long time during the first 1000 days of life (DOL) which is a critical period. Lack of parental knowledge will greatly affect children's nutritional intake. Therefore it is necessary to prevent stunting in children under five, either directly (specific nutrition intervention) or indirectly involving cross-sectors and communities in the provision of food, clean water and sanitation, poverty alleviation, education, social and so on. The purpose of this activity is to increase the knowledge of parents on how
\end{abstract}


important it is to maintain children's nutritional intake even during pregnancy to prevent stunting. The method used in this activity is counseling to parents of toddlers who carry out posyandu at Posyandu Melati 2, Sukajawa District regarding the importance of monitoring children's development and development by routinely checking them at the posyandu to see if there is a risk of stunting in toddlers. This activity was held on December 22, 2020 at Posyandu Melati 2, Sukajawa District. The result of this activity is the increased knowledge and insight of parents about the importance of providing good nutrition and coming to the posyandu to measure the height and weight of toddlers so that they can monitor the growth of their children and know what signs and symptoms arise in stunting in toddlers How to prevent.

Keywords: Penyeluhan, Stunting, Toddler

\section{PENDAHULUAN}

Di negara berkembang stunting menjadi masalah kesehatan masyarakat yang serius. Stunting disebabkan kekurangan asupan gizi dalam waktu lama pada masa 1000 hari pertama kehidupan (HPK) yang merupakan masa kritis. Balita setelah diukur panjang atau tinggi badan menurut umurnya, bila dibandingkan dengan standar baku WHO-MGRS (Multicentre Growth Reference Study) tahun 2005, nilai z-scorenya kurang dari -2SD dikatagorikan pendek, dan dikategorikan sangat pendek jika nilai z-scorenya kurang dari -3SD. (Kementrian Kesehatan RI, 2016)

Asupan gizi yang dibutuhkan untuk mencegah stunting berupa asupan gizi yang baik saat hamil, konsumsi tablet penambah darah yang cukup saat hamil, pemberian ASI kepada anak selama 6 bulan pertama, dan dilanjutkan dengan makanan pendamping ASI yang tepat sampai anak berusia 2 tahun. Faktorfaktor lain yang berpengaruh terhadap kejadian stunting adalah kemampuan tenaga kesehatan dalam mendeteksi kondisi stunting sejak dini, kebersihan air dan lingkungan, pola pengasuhan anak, tempat persalinan dan genetic (Indonesia, P. A. G. 2018).

Anak-anak pendek menghadapi risiko yang lebih besar untuk tumbuh menjadi orang dewasa yang kurang berpendidikan, miskin, kurang sehat dan lebih rentan terhadap penyakit tidak menular. Anak pendek merupakan prediktor buruknya kualitas sumber daya manusia, yang selanjutnya menurunkan kemampuan produktif suatu bangsa di masa yang akan datang (Kemenkes, 2012).

Selain itu masyarakat belum menyadari anak pendek merupakan suatu masalah, karena anak pendek di masyarakat terlihat sebagai anak-anak dengan aktivitas yang normal, tidak seperti anak kurus yang harus seger aditanggulangi. Demikian pula halnya gizi ibu waktu hamil, masyarakat belum menyadari pentingnya gizi selama kehamilan berkontribusi terhadap keadaan gizi bayi yang akan dilahirkannya kelak (Mitra, 2015)

Masa balita merupakan periode yang sangat peka terhadap lingkungan sehingga diperlukan perhatian lebih terutama kecukupan gizinya (Kurniasih, 2010). Masalah gizi terutama stunting pada balita dapat menghambat perkembangan anak, dengan dampak negatif yang akan berlangsung dalam kehidupan selanjutnya seperti penurunan intelektual, rentan terhadap penyakit tidak menular, penurunan produktivitas hingga menyebabkan kemiskinan dan risiko melahirkan bayi dengan berat lahir rendah (UNICEF, 2012; dan WHO, 2010). 
Status gizi ibu hamil sangat memengaruhi keadaan kesehatan dan perkembangan janin. Gangguan pertumbuhan dalam kandungan dapat menyebabkan berat lahir rendah (WHO, 2014). Penelitian di Nepal menunjukkan bahwa bayi dengan berat lahir rendah mempunyai risiko yang lebih tinggi untuk menjadi stunting (Paudel, et al., 2012). Panjang lahir bayi juga berhubungan dengan kejadian stunting. Penelitian di Kendal menunjukkan bahwa bayi dengan panjang lahir yang pendek berisiko tinggi terhadap kejadian stunting pada balita (Meilyasari dan Isnawati, 2014). Faktor lain yang berhubungan dengan stunting adalah asupan ASI Eksklusif pada balita. Penelitian di Ethiopia Selatan membuktikan bahwa balita yang tidak mendapatkan ASI eksklusif selama 6 bulan berisiko tinggi mengalami stunting (Fikadu, et al., 2014).Status sosial ekonomi keluarga seperti pendapatan keluarga, pendidikan orang tua, pengetahuan ibu tentang gizi, dan jumlah anggota keluarga secara tidak langsung dapat berhubungan dengan kejadian stunting. Hasil Riskesdas (2013) menunjukkan bahwa kejadian stunting balita banyak dipengaruhi oleh pendapatan dan pendidikan orang tua yang rendah. Keluarga dengan pendapatan yang tinggi akan lebih mudah memperoleh akses pendidikan dan kesehatan sehingga status gizi anak dapat lebih baik (Bishwakarma, 2011). Penelitian di Semarang menyatakan bahwa jumlah anggota keluarga merupakan faktor risiko terjadinya stunting pada balita usia 24-36 bulan (Nasikhah dan Margawati, 2012).

Kurang nya pengetahuan orang tua akan sangat berpengaruh pada asupan gizi anak. Oleh karenanya diperlukan upaya pencegahan terjadinya stunting pada balita baik secara langsung (intervensi gizi spesifik) maupun secara tidak langsung yang melibatkan lintas sektor dan masyarakat dalam penyediaan pangan, air bersih dan sanitasi, penangulangan kemiskinan, pendidikan, sosial dan sebagainya (Kementrian Kesehatan RI, 2016) yaitu terdapat hubungan yang signifikat antara pengetahuan ibu akan stunting dengan asupan gizi anak .

Berdasarkan permasalahan yang ada pada masyarakat dan untuk meningkatkan pengetahuan para orang tua betapa penting nya menjaga asupan gizi anak- anak bahkan pada saat kehamilan untuk mencegah stunting, maka program pengabdian masyarakat ini di fokuskan untuk menyelenggarakan penyuluhan pencegahan stunting di era pandemi dengan sasaran kepada anak prasekolah dan orang tua.

\section{MASALAH}

Alasan kami memilih melakukan penyuluhan di posyandu Melati II adalah karena masih kurangnya pengetahuan orang tua dan kesadaran orang tua tentang pentingnya deteksi dini Stunting pada balita serta bagaimana cara mencegah terjadinya stunting pada balita, yang dibuktikan dengan pertanyaan pra penyuluhan, masih banyak orang tua yang tidak mengetahui pentingnya hal tersebut. Maka diharapkan setelah diberikan penyuluhan ini, maka orang tua dapat mengetahui dan mengevaluasi diri mengenai pentingnya memonitoring tumbuh kembang anak dengan cara rutin memeriksakannya ke posyandu untuk melihat ada tidaknya resiko terjadinya stunting pada balita sehingga dapat dicegah jika terjadi penurunan garis pada pemeriksaan kartu menuju sehat. 


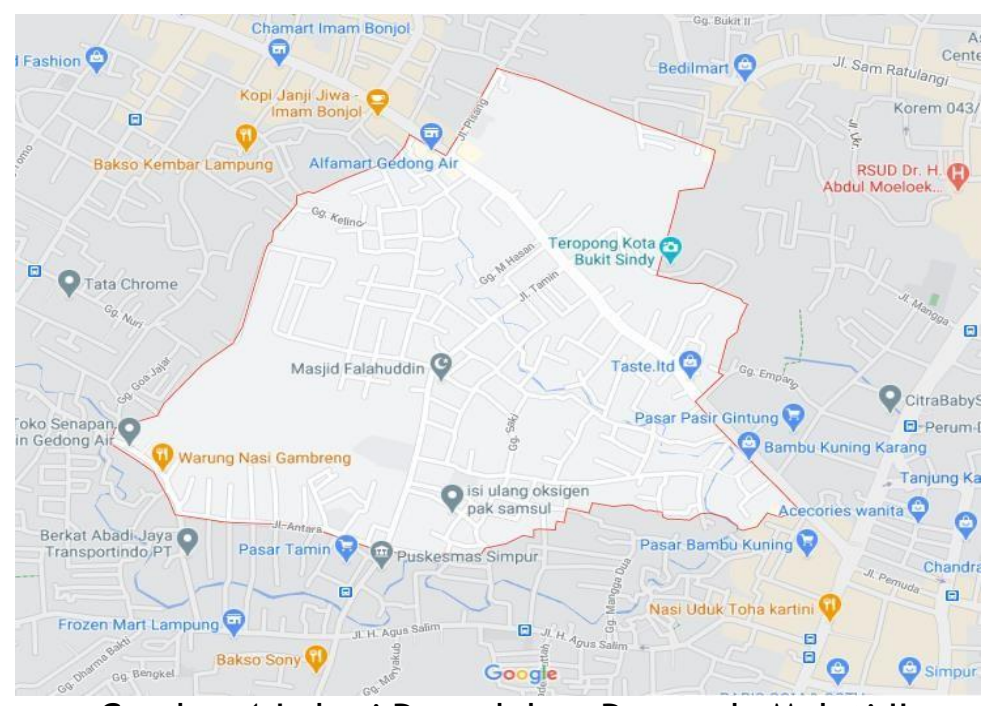

Gambar 1 Lokasi Penyuluhan Posyandu Melati II

\section{METODE}

1. Tujuan Persiapan

Tahap persiapan dari penyuluhan adalah pembuatan bahan penyuluhan berupa power point text yang mana dipresentasikan kepada ibu dan anak pada saat penyuluhan, persiapan tempat, alat - alat seperti proyektor, kursi, karpet, dan sebagainya. Peserta dalam penyuluhan ini adalah ibu dan anak di wilayah kerja Posyandu Melati II Kecamatan Sukajawa.

2. Tahap Pelaksanaan

Penyuluhan berjalan lancar dan dihadiri oleh 26 peserta. Media yang digunakan adalah pamphlet dan poster. Peserta aktif saat kegiatan dapat dilihat dari antusias peserta saat diskusi. Hasil akhir penyuluhan diadakan sesi tanya kepada ibu yang hadir, dan rata - rata dapat menjawab pertanyaan dengan tepat.

3. Evaluasi

a. Struktur

Peserta yang hadir sebanyak 26 orang. Waktu dan pelaksanaan dan setting tempat sudah dilaksanakan sesuai rencana dan perlengkapan yang dilakukan untuk penyuluhan sudah tersedia dan sudah digunakan sebagaimana mestinya. Disusi saat penyuluhan menarik karena bahasa yang digunakan komunikatif, selain itu pemilihan tema yaitu cegah stunting sangat menarik perhatian peserta. Antusias anak - anak juga terlihat sehingga proses edukasi lebih tersampaikan.

b. Proses

Pelaksanaan penyuluhan pukul

$10.00 \mathrm{~s} / \mathrm{d} 11.00 \mathrm{WIB}$. Sesuai dengan jadwal yang telah direncanakan.

c. Hasil

Meningkatnya pengetahuan dan wawasan orang tua tentang pentingnya pemberian nutrisi yang baik serta datang ke posyandu untuk mengukur tinggi badan dan berat badan balita agar dapat memonitoring pertumbuhan anak anaknya serta mengetahui tanda dan gejala apa saja yang timbul pada stunting pada balita dan bagaimana cara mencegahnya. 


\section{HASIL DAN PEMBAHASAN}

Metode pelaksanaan kegiatan ini dilaksanakan pada tanggal 22 Desember 2020 di Posyandu Melati 2 Kecamatan Sukajawa. Sasaran kegiatan ini ditujukan pada orang tua balita yang melaksanakan posyandu di Posyandu Melati 2 Kecamatan Sukajawa. Media yang digunakan pada penyuluhan ini berupa pamphlet dan poster materi tentang Edukasi Stunting Balita Pada Masa Pandemi. Dan metode yang digunakan yaitu berupa ceramah dan Tanya jawab mengenai Pencegahan Stunting Balita Pada Masa Pandemi.

Evaluasi pelaksanaan penyuluhan dilakukan sebelum dan setelah intervensi dengan mengajukan pertanyaan kepada tiap masing-masing orang tua yang menunjukkan peningkatan pengetahuan orang tua mengenai materi penyuluhan stunting pada balita. Pendidikan Kesehatan dengan melakukan penyuluhan merupakan intervensi yang tepat dilakukan pada orang tua balita karena akan memberikan pola piker yang baik yang berdampak pada setiap pengambilan keputusan dan dalam berprilaku. (Primantoro, dkk 2017).

Pada kegiatan ini juga dilakukan pemeriksaan Tinggi badan dan berat badan berdasarkan umur pada balita untuk melihat ada tidaknya indikasi Stunting pada anak tersebut dengan rata- rata hasil yang didapatkan yaitu masih dibatas normal pada garis kartu menuju sehat balita.

Berikut untuk Gambar Pelaksanaan Penyuluhan dan Pemeriksaan Berat Badan dan Tinggi Badan pada Balita di Posyandu Melati 2 Kecamatan Sukajawa

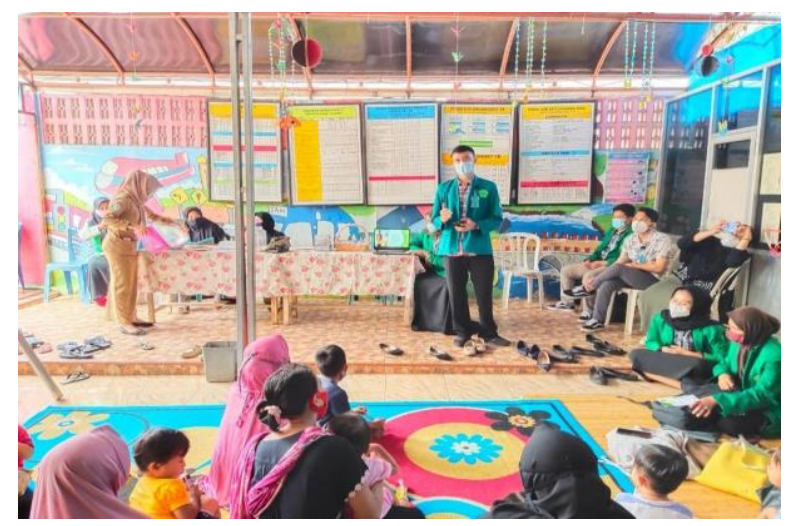

Gambar 2 Penyuluhan Edukasi Stunting pada Balita di Masa Pandemi

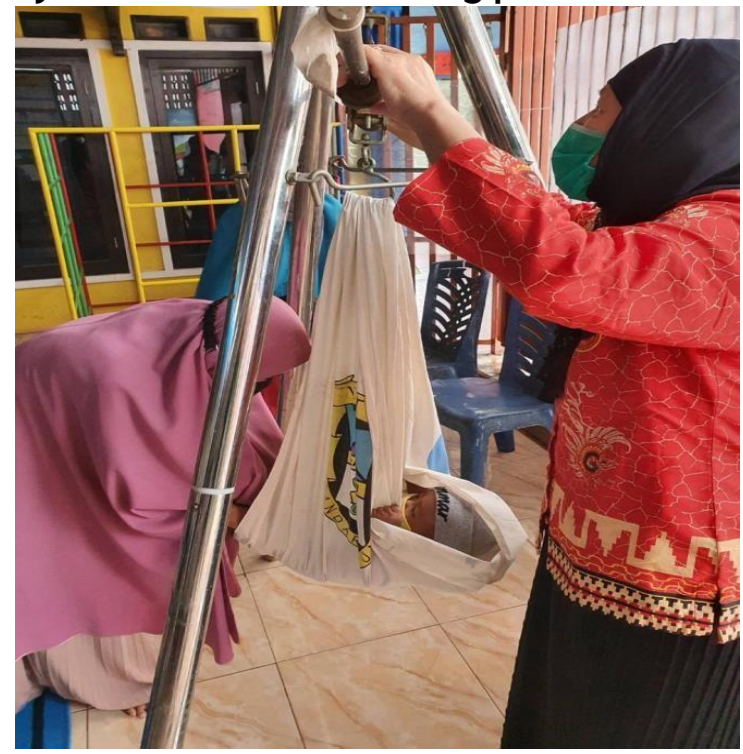

Gambar 3 Pemeriksaan Tinggi Badan dan berat Badan Pada Balita 


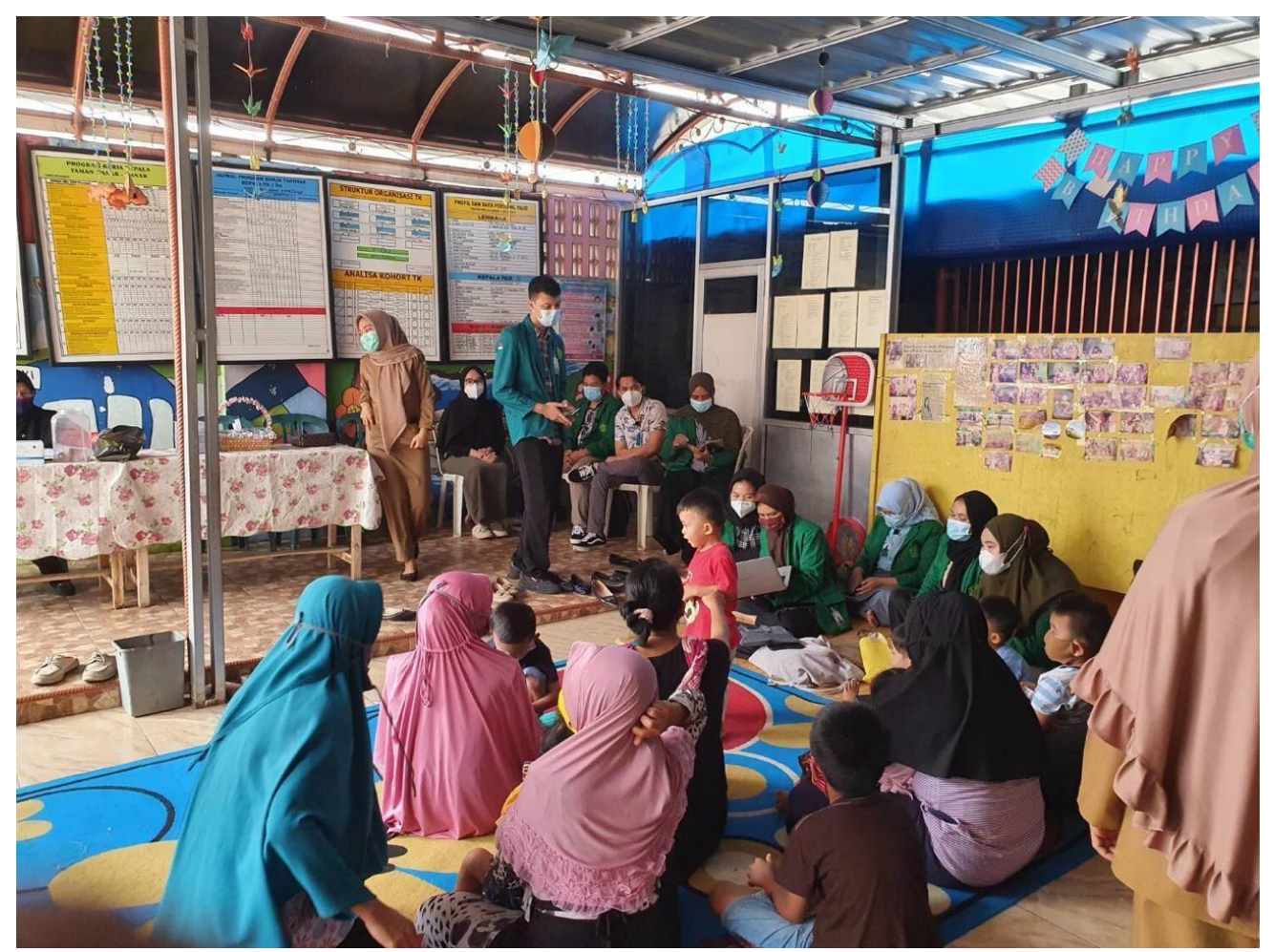

Gambar 4 Sesi Tanya Jawab \& Evaluasi Materi Penyuluhan kepada Orang tua

\section{KESIMPULAN}

Kegiatan pengabdian kepada masyarakat khususnya kepada orang tua balita dengam pemberian pendidikan kesehatan Edukasi Stunting di Era Pandemi ini berjalan dengan baik dan benar serta mengikuti protokol kesehatan di masa pandemic dengan Mencuci Tangan sebelum masuk ke area penyuluhan, Memakai Masker dan Menjaga Jarak . Peserta sangat aktif dan antusias dalam bertanya mengenai Stunting pada Balita dan dapat bekerjasama dengan baik. Hasil dari kegiatan ini yaitu meningkatnya pengetahuan dan wawasan orang tua tentang pentingnya pemberian nutrisi yang baik serta pentingnya datang ke posyandu untuk mengukur tinggi badan dan berat badan balita agar dapat memonitoring pertumbuhan anakanaknya serta mengetahui tanda dan gejala apa saja yang timbul pada stunting pada balita dan bagaimana cara mencegahnya. Adapun namanama pelaksana kegiatan penyuluhan yaitu antara lain: Dwi Robbiardy Eksa selaku dosen pembimbing, Indri Aprianti (17310131) selaku mahasiswa, Intan Utami Putri (17310132) selaku mahasiswa, lqbal Al-Yuzri selaku mahasiswa (17310133), Itsna Annisa(17310134) selaku mahasiswa, Ivana Olga (17310135) selaku mahasiswa, Izzati Sabila (17310136) selaku mahasiswa, Jane Elvina(17310137) selaku mahasiswa, Jenerio Panggabean (17310138) selaku mahasiswa, Kalesa Ariantika (17310139) selaku mahasiswa, Kartika Dwi Putri (17310140) selaku mahasiswa, Kevin Yoshua Padang (17310141) selaku mahasiswa. 


\section{DAFTAR PUSTAKA}

Bishwakarma, R. (2011). Spatial Inequality in Children Nutrition in Nepal: Implications of Regional Context and Individual/Household Composition. (Disertasi, University of Maryland, College Park, United States). Diakses dari http://hdl.handle.net/1903/11683

Fikadu, T., Assegid, S. \& Dube, L. (2014). Factor associated with stunting among children age 24 to 59 months in Meskan District, Gurage Zone, South Ethiopia: A case-control study. BMC Public Health, 14(800). Diakses dari http://www.biomedcentral.com/1471-2458/14/800.

Indonesia, P. A. G. (2018). Stop stunting dengan konseling gizi. Penebar PLUS+. Jurnal Kesehatan Komunitas. (2015). Mitra, Permasalahan Anak Pendek (Stunting) Dan Intervensi Untuk Mencegah Terjadinya Stunting Vol. 2, No. 6, Mei

Kemenkes. (2012). Gizi Ibu \& Anak. Unicef Indonesia, Oktober 20 (Gizi Ibu \& Anak)

Kementrian Kesehatan RI. (2016). Situasi balita pendek. Info Datin, 2442- 7659. https://doi.org/ISSN 2442-7659

Kurniasih dkk. (2010). Sehat dan bugar berkat gizi seimbang. Jakarta: Gramedia.

Meilyasari, F. \& Isnawati, M. (2014). Faktor risiko kejadian stunting pada balita usia 12 bulan di Desa Purwokerto Kecamatan Patebon, Kabupaten Kendal. Journal ofNutrition College, 3(2), 16-25. Diakses dari http://www,ejournal-s1.undip.ac.id

Paudel, R., Pradhan, B., Wagle, R. R., Pahari, D.P., \& Onta S. R. (2012). Risk factors for stunting among children: A community based case control study in Nepal. Kathmandu University Medical Journal, 10(3), 18-24.

UNICEF. (2012). Ringkasan kajian gizi Oktober 2012. Jakarta: UNICEF Indonesia. WHO. (2010). Nutrition landscape information system (NLIS) country profile indicators: Interpretation guide. Geneva: World Health Organization.

WHO. (2014). WHA global nutrition targets 2025: Stunting policy brief. Geneva: World Health Organization. 